\title{
A EDUCAÇÃO DE JOVENS E ADULTOS NA PERSPECTIVA DA FORMAÇÃO HUMANA: DESAFIOS NO CONTEXTO DAS RELAÇÕES FLEXÍVEIS DE TRABALHO
}

\author{
LA EDUCACIÓN DE LOS JÓVENES Y ADULTOS EN LA PERSPECTIVE DE LA \\ FORMACIÓN HUMANA: DESAFÍOS EN EL CONTEXTO DE LAS RELACIONES \\ FLEXIBLES DE TRABAJO
}

\begin{abstract}
THE EDUCATION OF YOUNG AND ADULTS IN THE PERSPECTIVE OF THE HUMAN FORMATION: CHALLENGES IN TE CONTEXT OF THE FLEXIBLE RELATIONS OF WORK
\end{abstract}

\author{
Carlos Soares BARBOSA ${ }^{1}$
}

RESUMO: Com base no pensamento de Antonio Gramsci, o presente artigo visa a refletir o papel econômico, político e social da Educação de Jovens e Adultos (EJA) no contexto da flexibilização no Brasil, produto das transformações ocorridas no mundo da produção e do trabalho nas últimas décadas. Para isso, discute a direção ética e política da EJA no contexto da estrutura dual do ensino e da reforma educacional brasileira, ocorrida no governo de Fernando Henrique Cardoso, para em seguida, e contrapondo-se a essa proposta, apresentar a concepção de EJA na perspectiva da formação humana, integral e para além dos interesses do mercado e do capital. Trata-se de reflexões tecidas a partir dos dados da pesquisa realizada em 2017, que contou com a participação de 8 professores e 67 estudantes do $1^{\circ}$ e $2^{\circ}$ segmentos do Ensino Fundamental de duas escolas pertencentes ao Programa de Educação de Jovens e Adultos da rede municipal do Rio de Janeiro.

PALAVRAS-CHAVE: Educação de jovens e adultos. Acumulação flexível. Formação humana. Antonio gramsci.

RESUMEN: Basado en el pensamiento de Antonio Gramsci, el propósito de este artículo es reflejar el rol económico, político y social de la Educación de Jóvenes y Adultos (EJA) en el contexto de la flexibilización en Brasil, producto de las transformaciones que ocurrieron en el mundo de la producción y del trabajo en las últimas décadas. Para eso, discute la dirección ética y política de la EJA en el contexto de la estructura dual de la enseñanza y de la reforma educativa brasileña, que sucedió en el gobierno de Fernando Henrique Cardoso, para luego, y oponiéndose a esta propuesta, presentar la concepción de EJA en la perspectiva de la formación humana, integral y más allá de los intereses del mercado y el capital. Se trata de reflexiones basadas en datos de la encuesta realizada en 2017, que contó con la participación de 8 docentes y 67 alumnos de dos escuelas pertenecientes al Programa de Educación de Jóvenes y Adultos de la red municipal de Rio de Janeiro.

${ }^{1}$ Universidade Estadual do Rio de Janeiro (UERJ), Rio de Janeiro - RJ - Brasil. Professor Adjunto da Faculdade de Educação da UERJ-Maracanã, Departamento de Estudos da Educação Inclusiva e Continuada. Pesquisador das áreas de Educação de Jovens e Adultos e de Trabalho e Educação. ORCID <https://orcid.org/0000-00034519-5174>. E-mail: profcarlossoares@gmail.com 
PALABRAS CLAVE: Educación de jóvenes y adultos. Acumulación flexible. Formación humana. Antonio Gramsci.

ABSTRACT: Based on the thinking of Antonio Gramsci, this article aims to reflect the economic, political and social role of the Youth and Adult Education (EJA) in the context of flexibilization in Brazil, a product of the transformations that occurred in the world of the production and of the work in the last decades. For that, it discusses the ethical and political direction of the EJA in the context of the dual structure of the teaching and of the Brazilian education reform, that happened in the government of Fernando Henrique Cardoso, for soon afterwards, and opposing this proposal, to present the conception of EJA in the perspective of the human formation, integral and beyond of the interests of the market and the capital. These are reflections based on data from the survey conducted on 2017, wich counted on the 8 teachers' participation and 67 students from two schools belonging to the Youth and Adult Education Program of the the municipal network of Rio de Janeiro.

KEYWORDS: Youth and adult education. Flexible accumulation. Human formation. Antonio Gramsci.

\section{Introdução}

Por que pais e/ou demais responsáveis matriculam seus filhos na escola? Por que jovens e adultos afastados da escola têm feito o movimento de retorno aos bancos escolares nas últimas décadas? As respostas para essas questões, que a priori parecem simples e de fácil dedução, nos tencionam a refletir sobre o papel político-social da escola no atual regime de acumulação flexível (HARVEY, 1994). Excetuando as obrigações legais no caso de crianças e adolescentes, determinadas pelo Estatuto da Criança e do Adolescente (ECA), as respostas têm sido quase que consensual para o retorno de jovens e adultos aos bancos escolares, qual seja, "a conquista de um bom emprego", ter "melhor condição de inserção no mercado de trabalho", "oferecer uma vida melhor para família" e/ou "ser alguém na vida". É também o que demonstra os dados da pesquisa que realizamos em 2017, por meio de entrevistas de roteiros semi-estruturados e de questionários com perguntas abertas e fechadas, aplicados a oito professores e a 67 estudantes de duas escolas do Ensino Fundamental pertencentes ao Programa de Educação de Jovens e Adultos (PEJA) do município do Rio de Janeiro.

A predominância das respostas sinalizadas, independente da faixa etária dos sujeitos, das condições socioeconômicas e/ou da etapa de escolaridade, demonstra o quanto a ideologia do capital humano se mantém fortalecida no senso comum e tem sido retroalimentada nos diversos aparelhos de hegemonia pelos intelectuais orgânicos do capital (individuais e coletivos) como forma de impedir o desvelamento das causas estruturais dos problemas RIAEE - Revista Ibero-Americana de Estudos em Educação, Araraquara, v. 14, n. 1, p. 63-76, jan./mar., 2019. E-ISSN: $1982-5587$. DOI: $10.21723 /$ riaee.v14i1.11114 (cc) BY-NC-sA 
sociais, assim como a compreensão mais ampla do papel político-social da escola na perspectiva da formação humana. O fundamento da referida teoria consiste na ideia de que o investimento que as pessoas fazem em si mesmas em educação (instrução escolar), saúde e qualificação profissional se constitui em um capital humano e, portanto, em investimento com retornos equivalentes a outros bens de produção (SCHULTZ, 1973). A partir de então, políticos e intelectuais do sistema capitalista passaram a considerá-la a chave para que países e indivíduos saíssem da pobreza, divulgando "a crença que pela educação poderiam integrar a todos no mercado, ainda que de modo desigual, já que para estes a desigualdade resulta do não empenho dos pobres na gestão de suas vidas" (FRIGOTTO, 2016, p. 27).

Apesar da não correspondência linear na realidade concreta entre o aumento da escolarização/qualificação profissional/inserção no mercado de trabalho, ou a linearidade imediata entre aumento da escolaridade/qualificação profissional/aumento de renda, como demonstram diversos estudos (POCHMANN, 2004; DEL PINO, 2002), tal associação continua fortemente presente no senso comum e tem servido para justificar a importância econômico-social da escola, tanto por parte de professores, pais e representantes do poder público, quanto de representantes das mais variadas organizações da sociedade civil.

No atual contexto de desemprego estrutural e de crescimento das relações de trabalho flexíveis e precárias, caracterizadas pela terceirização, trabalho de tempo parcial, autônomo e/ou desregulamentado, fato que tende a se agravar com a reforma trabalhista implementada no governo Temer por meio da Lei n. 13.467/2017, o investimento em capital humano por parte dos trabalhadores se constitui em critério privilegiado para o processo de seleção das poucas vagas abertas no mercado de trabalho formal. Porém, mais do que certezas, essas condicionalidades acenam apenas para a possibilidade de empregabilidade, o que significa estarem disponíveis para todas as mudanças, prontos para trocarem constantemente de trabalho.

Face à instituição do regime de acumulação flexível e à desintegração da promessa integradora da escola (GENTILI, 1998) os empresários e seus órgãos econômicocorporativos, como a FIESP e o Movimento “Todos pela Educação", reivindicam da educação escolar a formação de trabalhador de novo tipo: trabalhadores "flexíveis", polivalentes, conformados com a restrição de direitos e adaptáveis às flutuações do mercado, em detrimento de um processo formativo que proporcione as ferramentas teóricas que os possibilite a ler o mundo e nele intervir, com vistas à transformação das vigentes relações de exploração e à promoção de novas relações sociais de produção. Essas são problematizações 
que precisam ser consideradas pelos professores da EJA, sobretudo pelo fato de a modalidade ser constituída majoritariamente por trabalhadores que trazem em seus corpos o significado objetivo/subjetivo da expropriação do capital sobre o trabalho.

Considerando o trabalho como atividade essencialmente humana, ação criativa e construtora da produção/reprodução da existência, o argumento aqui defendido é o de que as reflexões pertinentes ao mundo do trabalho precisam ganhar espaço nas atividades pedagógicas desenvolvidas na EJA e nas demais etapas e modalidades da educação escolar. Não no sentido de reduzir o direito à educação à instrumentalidade da formação para o trabalho, por meio de um viés instrumental, economicista e fetichizado na qual a educação é apresentada como redentora das mazelas enfrentadas no mercado de trabalho e imputando às pessoas a responsabilidade de superá-las pelo uso de suas capacidades individuais, mas por compreender a escola na perspectiva gramsciana, isto é, enquanto espaço de disputa, dinâmico e contraditório por se encontrar imersa no conflito de interesses presentes na sociedade. Desse modo, ao mesmo tempo em que a escola possui importância política e estratégica para a manutenção dos interesses do capital e a conservação da ordem econômica-politica-social instituída, como evidenciam algumas ações como o "Projeto Escola Sem Partido" e a centralidade do Estado nos processos da reforma curricular do Ensino Médio, materializada inicialmente por meio da Medida Provisória n. 746/2016, nela há também espaços de resistências e de ações contra-hegemônicas, possuindo papel importante para a transformação social.

Como todo aparelho de hegemonia e de disputa de projetos políticos e societários, a escola continua a ser reivindicada pelos trabalhadores. Conforme dados coletados em nossa pesquisa, jovens e adultos que se encontram em situação de desemprego ou submetidos a trabalhos precários justificam seu retorno aos bancos escolares como forma de enfrentamento das mazelas vivenciadas no mercado, sem problematizar a ineficiente política pública de geração de trabalho e renda, o crescimento do trabalho informal e das demais relações flexíveis de trabalho, a atual ofensiva do capital contra os direitos trabalhistas e sociais, conjugada pela criminalização dos movimentos sociais.

À luz dessas considerações iniciais, interessa-nos reafirmar o caráter emancipador da EJA, concebida sob a perspectiva da formação humana, de direito subjetivo e como condição necessária para a plena participação dos sujeitos na sociedade, em detrimento da concepção instrumental - preparadora de mão de obra conformada às demandas do mercado. Para o alcance desse objetivo, na primeira parte refletimos sobre o papel político-social da referida 
modalidade na estrutura dual de ensino brasileira e a configuração que assume após a reforma educacional implementada nos governos de Fernando Henrique Cardoso, para em seguida, e em diálogo com os dados da pesquisa, apresentar a concepção de EJA na perspectiva da formação humana, integral e para além dos interesses do mercado e do capital, ancorada no pensamento da Antonio Gramsci.

\section{A direção ética e política da EJA na dualidade estrutural e no regime de acumulação flexível}

A educação escolar é um direito humano garantido na Constituição Federal (BRASIL, 1988) e reafirmado na Lei de Diretrizes e Bases da Educação (BRASIL, 1996), reconhecendo como dever do Estado a oferta de educação para todas as pessoas, inclusive àquelas que não tiveram condições de acesso e permanência na idade apropriada. Porém, esse reconhecimento jurídico-legal não se deu de modo natural. É fruto das experiências acumuladas nos movimentos de educação popular das décadas de 1950 e 1960 e retomadas nas lutas protagonizadas pelas distintas organizações da sociedade civil na década de 1980, período em que se reacendeu a esperança de se construir uma sociedade democrática, justa e integradora.

De certo, após os retrocessos efetuados na educação e nas demais áreas da vida coletiva provocado pelo golpe civil-militar, em 1964, a década de 1980 pode ser considerada uma fase rica para a educação brasileira, momento em que as concepções de matrizes marxianas e gramscianas, como "formação integral", "educação unitária", "politécnica", "omnilateral" e "trabalho como princípio educativo" foram retomadas pelos teóricos do pensamento histórico-social e disputaram o consenso durante o processo de elaboração do texto dedicado à educação na nova Constituição e durante a elaboração da nova LDB. A defesa dessas concepções político-filosóficas não significou apenas a crítica à profissionalização compulsória garantida na Lei $n^{\circ}$. 5.692/71, mas, sobretudo, a luta contra a estrutura dual do ensino brasileiro, conformada na existência de modelos de escolas e de processos formativos ofertados diferenciadamente de acordo com a classe social dos sujeitos. De um lado, um tipo de formação destinada aos que produzem a vida e a riqueza da sociedade; e, do outro, um tipo de formação destinada às elites dominantes e dirigentes.

Historicamente, a dualidade estrutural da educação brasileira não é de difícil constatação empírica. Trata-se de manifestação específica do modo de produção capitalista que reproduz no âmbito educacional a divisão existente nas sociedades de classes. Uma estrutura educacional a serviço da manutenção das desigualdades econômicas, sociais e RIAEE - Revista Ibero-Americana de Estudos em Educação, Araraquara, v. 14, n. 1, p. 63-76, jan./mar., 2019. E-ISSN: 1982-5587. DOI: $10.21723 /$ riaee.v14i1.11114 
políticas internas e externamente; produto e produtor da própria divisão internacional do trabalho. Como explicita Arrighi (1997), em um pólo, um conjunto de países que constituem o núcleo orgânico das economias capitalistas, onde se realizam as atividades cerebrais associadas ao fluxo de inovação, envolvendo novos métodos de produção, novas fontes de suprimento e novas formas de organização -; e no outro, os núcleos periféricos e semiperiféricos, que realizam as atividades dominantemente neuromusculares, condenadas a pouquíssima inovação e investimento em educação, ciência e tecnologia.

Com base na análise do referido autor, também não é difícil identificar a função que historicamente o Brasil desempenha na divisão internacional do trabalho, já que a diversificação do parque industrial brasileiro, nas décadas de 1950-1970, e o projeto novodesenvolvimentismo do governo Lula não vieram conjugados com os interesses das classes dominantes e dirigentes, de matriz colonialista, autoritária e escravocrata em romper com a especificidade brasileira de "capitalismo dependente" (FERNANDES, 1975). Esta particularidade brasileira na totalidade das relações de produção e do desenvolvimento das forças produtivas mundiais tem servido de justificativa para negar a oferta de formação humanista e técnico-científica para todos os cidadãos brasileiros, considerada desperdiço de dinheiro público na concepção dos neoliberais e seus intelectuais orgânicos, uma vez que a maioria dos postos de trabalhos abertos em nosso país é de trabalho simples, o que demanda uma formação simples para grande parte dos trabalhadores. Para esses, basta um padrão mínimo exigido para participar da vida social e produtiva - rudimentos de leitura e escrita e as operações básicas da matemática -, complementado por qualificação profissional de curta duração e baixo custo.

As precárias instalações físicas das escolas destinadas a este segmento seguem essa lógica, daí os baixos investimentos públicos destinados à criação/manutenção de laboratórios de ciências e de informática, à realização de atividades extraclasses e/ou à construção de quadras poliesportivas. Realidade agravada nas escolas que ofertam a EJA, sobretudo após o veto da participação da modalidade no Fundo Nacional de Desenvolvimento do Ensino Fundamental e Valorização do Magistério (FUNDEF), que vigorou entre 1998-2006. Como demonstram os dados publicados pelo Ministério da Educação, em 2006, apenas 27\% das escolas que possuíam matrículas na EJA contavam com biblioteca e em somente $12 \%$ delas os educandos tinham acesso a computador (MEC, 2009) ${ }^{2}$. Apesar da inclusão da EJA no Fundo

${ }^{2}$ Disponível em: [http://portal.mec.gov.br/dmdocuments/confitea_docfinal.pdf]. Acesso em out. 2009. 
de Manutenção e Desenvolvimento da Educação Básica e de Valorização dos Profissionais da Educação (FUNDEB), em 2007, esta realidade pouco se alterou, e tem se agravado durante o governo de Michel Temer, mediante a retomada da visão economicista da educação, concebida por meio da relação custo-benefício, e em decorrência da falsa racionalidade dos gastos públicos preconizada no discurso governamental. Constatamos essa realidade nas escolas pesquisadas.

Os intelectuais orgânicos do capital defendem processos formativos diferentes, justificados em nome da equidade e do (suposto) respeito às diferenças. De certo, a equidade é algo importante para pensarmos a EJA, especialmente quando reconhecemos a multiculturalidade presente na modalidade, o que nos leva a considerar a diversidade existente nos modos de sentir, viver e estar no mundo dos distintos sujeitos. Por consequência, nos leva a respeitar as múltiplas identidades e suas expectativas em relação à escola, à vida, ao futuro, bem como os diferentes ritmos de aprendizagem, o que exige do professor o uso de metodologias diferenciadas por entender que todas as pessoas têm a capacidade de aprender em qualquer etapa da vida. No regime de acumulação flexível, porém, a equidade é reafirmada no intuito de manter a desigualdade educacional, fato que contribui para a permanência das desigualdades sociais e a polarização da mão de obra, à medida que se oferta, com base em Kuenzer (1999), formação simplificada, de curta duração e de baixos custos às pessoas em condição de desemprego ou submetidas a trabalhos precários, e educação científico-tecnológica mais avançada para um pequeno número de trabalhadores.

Ademais, a ideologia do capital humano reforça a crença de que o problema do desemprego reside na baixa escolaridade e/ou pouca qualificação profissional dos trabalhadores, o que alimenta a expectativa de jovens e adultos em relação à escola e/ou a um curso de formação profissional, como constatamos na pesquisa. No entanto, como argumenta Del Pino (2002), diante da impossibilidade concreta de satisfação de empregos para todos no capitalismo, é ingênuo acreditar que as distorções do mercado de trabalho possam ser corrigidas em função da qualificação dos trabalhadores. Nesta mesma direção, Castel (1998, p. 521) afirma ser "ilusório deduzir que os não empregados possam encontrar um emprego simplesmente pelo fato de uma elevação do nível de escolaridade". O mesmo conclui Souza (2011), em estudo realizado com base no perfil dos trabalhadores desempregados no município de Nova Iguaçu (RJ), atendidos em 2008 pelo serviço de intermediação de mão-deobra, oferecido pela hoje extinta Secretaria Municipal de Desenvolvimento Econômico e Social (SEMDES). O autor registra que entre os 21.613 indivíduos desempregados existentes 
no cadastro de 2008 , dos quais $28,6 \%$ eram jovens entre 18 e 28 anos, $70 \%$ do total estavam estudando e $41 \%$ tinham o ensino médio completo, o que o leva a concluir que a questão do desemprego no município não reside na falta de qualificação, mas sim na falta de postos de trabalho suficientes para atender a demanda.

Neste sentido, defendemos uma Educação de Jovens e Adultos que não se atrele aos interesses do mercado e do capital, mas sim na perspectiva da formação humana. Isto é, que ao desenvolver as dimensões da cultura, ciência, tecnologia, trabalho, afetividade e política possibilitem os sujeitos a desvelar a realidade social e a se posicionar na luta contra o trabalho alienado e a dualidade educacional, próprias das sociedades de classes. A "escola unitária" proposta por Gramsci apresenta os pressupostos da formação aqui defendida, cuja concepção expressa o princípio da educação como direito de todos e de que todos tenham acesso aos conhecimentos, à cultura e às mediações necessárias para trabalhar e produzir a existência e a riqueza social. Uma educação que, ao propiciar aos sujeitos o acesso aos conhecimentos e à cultura construídos pela humanidade, lhes dê condições de escolhas e a construção de caminhos para a produção da vida. Esse caminho é o trabalho, entendido no seu sentido ontológico, como realização e produção humana, e como práxis econômica.

\section{A “escola unitária" de Gramsci: princípios para pensar a EJA na perspectiva da formação humana}

A partir da compreensão de que o trabalho é atividade essencialmente humana, o trabalho é uma das dimensões a ser desenvolvida na educação escolar. Não se trata, porém, de uma educação unilateral, preocupada apenas com a formação de mão-de-obra para o mercado de trabalho e a transmissão dos valores que legitimem o capitalismo, mas a formação que pressupõe o "trabalho como princípio educativo" (GRAMSC, 1995), por entender que o trabalho é parte fundamental da ontologia do ser social; atividade pela qual o ser humano se humaniza, se cria, se expande em conhecimento e se aperfeiçoa.

Em oposição à concepção instrumental e interessada da educação escolar capitalista, Marx (1978) defendia uma educação voltada para a formação de homens completos, que trabalham "não só com as mãos, mas com o cérebro, e que consciente do processo que desenvolve, domina-o e não é por ele dominado" (MANACORDA, 1991, p. 95). É a unilateralidade reproduzida pela educação liberal que Marx combate, concebendo, em contrapartida, a educação omnilateral, que ao romper com a separação entre trabalho manual e trabalho intelectual possibilitaria o desenvolvimento de todas as potencialidades humanas, 
uma vez que seu conteúdo e método fundamentam-se na união entre ciência, trabalho e ensino tecnológico (teórico e prático).

Gramsci (1995), adequando as idéias de Marx para análise das sociedades européias das primeiras décadas do século $\mathrm{XX}$, também propõe a integração entre ensino e trabalho, mas critica a tendência criada com o surgimento das indústrias modernas, que passou ser a de:

[...] abolir qualquer tipo de escola "desinteressada" (não imediatamente interessada) e "formativa", ou conservar delas tão-somente um reduzido exemplar destinado a uma pequena elite que não deve pensar em se preparar para um futuro profissional, bem como a de difundir cada vez mais as escolas profissionais especializadas, nas quais o destino do aluno e sua futura atividade são predestinados (GRAMSCI, 1995, p. 118).

Para o referido autor, a escola das classes trabalhadoras deveria ser "desinteressada", isto é, despida do utilitarismo que visa apenas à formação rápida da mão-de-obra minimamente qualificada para o trabalho. E como para Gramsci todos os homens são intelectuais, visto que o trabalho manual mais primitivo contém em si um aspecto intelectual, defende a escola que une e integra o trabalho manual e o trabalho intelectual com o objetivo de formar homens completos. Neste sentido, propõe uma escola:

[...] de formação humanista (entendido o termo "humanismo" em sentido amplo) ou de cultura geral que deveria se propor a tarefa de inserir os jovens na atividade social, depois de tê-lo levado a um certo grau de maturidade e capacidade, à criação intelectual e prática e a uma certa autonomia na orientação e iniciativa (GRAMSCI, 1995, p. 121).

Ao defender a formação geral, Gramsci não se descompromete com o desenvolvimento científico e tecnológico. Pelo contrário; sua tese é de que o trabalho se constitua no princípio educativo da ação pedagógica. Através de um sistema educacional não mais pautado na dualidade, acreditava ser possível conduzir os trabalhadores à superação do trabalho alienado e das demais desigualdades sociais através de sua ação política. Para ele, a democracia não consiste apenas em proporcionar "que um operário manual se torne qualificado, mas que cada cidadão possa se tornar governante e que a sociedade o coloque, ainda que "abstratamente" nas condições gerais de poder fazê-lo" (GRAMSCI, 1995, p. 137). Daí considerar que a proliferação das escolas reservadas às massas nada tinha de democrático, visto que, em vez de assegurar a cada governado a aprendizagem e a preparação técnica necessária ao fim de governar, a restringe a um seleto grupo. 
Neste sentido, Gramsci reivindica para os trabalhadores uma escola que assegure a autoformação e valorize o conhecimento do aluno e integre-o ao processo pedagógico. Que “conduza o jovem até o limiar da escolha profissional, formando-o, nesse meio tempo, como um homem capaz de pensar, de estudar, de dirigir, ou de controlar quem o dirige" (GRAMSCI, 1995, p. 136). Em síntese, uma escola comprometida com a formação "de um novo tipo de homem, que seja especialista e ao mesmo tempo dirigente".

Por conceber a importância política da escola para a classe trabalhadora, Gramsci rejeita o "espontaneísmo que se traduz no abandono do jovem aos influxos casuais do ambiente, na renúncia de educar" (MANACORDA 1990, p. 162). Para o referido autor, a escola das classes subalternas deve ser de noções rigorosas, por entender:

[...] que o estudo é também um trabalho, não só muscular-nervoso mas intelectual; é um processo de adaptação, é um hábito adquirido com esforço, aborrecimento e mesmo sofrimento. A participação das mais amplas massas na escola média leva consigo a tendência a afrouxar a disciplina do estudo, a provocar "facilidades". Muitos pensam, inclusive, que as dificuldades são artificiais, já que estão habituados a só considerar como trabalho e fadiga o trabalho manual [...] Se se quiser criar uma nova camada de intelectuais chegando às mais altas especializações, próprias de um grupo social que tradicionalmente não desenvolveu as aptidões adequadas, será preciso superar dificuldades inauditas (GRAMSCI, 1995, p. 138-139).

Assim como Gramsci, os teóricos do pensamento histórico-crítico contemporâneo também ressaltam a dimensão política da escola. Defendem uma educação que atue com fins a transformar o trabalhador em um agente que pensa e age no intuito de modificar a si e o seu meio (FREIRE, 1980). Esta é a perspectiva a qual concebemos a função política e social da EJA, sobretudo, por ser a modalidade constituída por trabalhadores-estudantes, cuja relação entre educação e mundo do trabalho ocorre de forma imediata e contraditória. Desse modo, para os sujeitos da EJA o sentido do conhecimento adquirido na escola não está em proporcionar, primeiro, a compreensão geral da vida social e, depois, instrumentalizar-se para o exercício profissional, como ocorre com a educação de crianças e adolescentes. A escola precisa lhes garantir, de forma imediata, as ferramentas teóricas que lhes possibilitem analisar e compreender a realidade pessoal, econômica e social a fim de nela intervir de forma consciente. Daí a importância dos conteúdos escolares possuírem significado social para os estudantes da EJA. 
Quando analisamos os dados da pesquisa empírica realizada, verificamos que entre os 67 estudantes participantes, todos pertencentes à população economicamente ativa, na faixa etária entre 18 e 43 anos, 26 deles (39\%) se encontravam em situação de desemprego, sendo 18 deles abaixo dos 30 anos de idade. Dos estudantes inseridos no mercado de trabalho, 28 encontravam-se no mercado de trabalho formal (42\%), com alguns direitos trabalhistas garantidos, ao passo que 13 estudantes (19\%) exerciam atividades no mercado informal, especialmente as jovens entre 18 e 25 anos.

Em relação à renda familiar dos sujeitos pesquisados, 42 estudantes (62\%) informaram ser composta de um salário mínimo, enquanto 6 indicaram que era constituída por menos de um salário e 14 (21\%) indicaram que a renda familiar correspondia entre 2 e 3 salários. Não obstante cinco estudantes não tenham informados sua renda familiar, os dados reforçam a enorme dívida social do país com expressivo contingente populacional, o que nos leva a compreender a EJA como uma política de ação afirmativa e de inclusão social.

Sobre o retorno à vida escolar, para $46 \%$ dos respondentes a expectativa em "melhorar de vida" foi o principal motivo, ao passo que "terminar os estudos" é entendido para 54\% dos jovens e adultos enquanto estratégia de enfrentamento às dificuldades de inserção e permanência no mercado de trabalho. É por esta razão que 57 estudantes (85\%) disseram pretender continuar os estudos e cursar o Ensino Médio e, entre eles, 7 (12\%) já pensavam em cursar o Ensino Superior, o que não deixa de ter um aspecto positivo.

As respostas dos estudantes sobre "os motivos que os fizeram voltar/continuar estudar" e sobre os "objetivos e sonhos futuros" demonstram o quanto a teoria do capital humano - e consigo a concepção da educação como redentora das mazelas enfrentadas no mercado de trabalho - ainda é bastante forte no senso comum. Não se trata de negar a importância da escola e da escolarização, mas o fato de que ao internalizarem acriticamente os discursos de diferentes sujeitos sociais, inclusive de alguns professores que justificam os altos índices de desemprego em nome da baixa escolaridade e da pouca (ou ausente) qualificação profissional, os estudantes não só se autoculpabilizam pelas mazelas por eles vividas, como isentam de responsabilidade o projeto político e societário em hegemonia e a ineficiente política de geração trabalho e renda. Criam, assim, expectativas que extrapolam as funções da escola, já que ela sozinha não é capaz de mudar as distorções e as desigualdades inerentes ao sistema capitalista. Expectativas que (mais) uma vez frustradas contribuem para a sua baixa autoestima, dificultando sua autonomia e maturidade política e intelectual. 


\section{Considerações finais}

O presente texto buscou refletir a EJA para além das questões mercadológicas, por entender ser esta uma concepção restrita e utilitária a ser superada não só no campo das políticas públicas, mas nas práticas político-pedagógicas executadas em muitas escolas, que sem problematizar a crescente exploração dos trabalhadores na atual configuração das relações de trabalho acabam por naturalizá-las, contribuindo para a conformação dos sujeitos à ordem econômica, político e social de forma acrítica. Diferentemente do pragmatismo utilitarista que a modalidade tem sido tratada no âmbito das políticas públicas e nos discursos de diferentes atores sociais, a concebemos na perspectiva da formação humana, voltada para o desenvolvimento das múltiplas dimensões do homem, inclusive o trabalho, por entendê-lo, com base no materialismo histórico-dialético, como produto do homem e ao mesmo tempo produtor do ser, da cultura e da civilização humana.

Conceber a EJA na perspectiva da formação humana incide pensar para além de uma educação conformadora, embora saibamos que a alienação ocorrida no/pelo trabalho capitalista não acabará apenas com a realização de mudanças no processo educativo. Todavia, como afirma Ciavatta (2005, p. 102), "se a educação é incapaz de mudar a sociedade desigual em que vivemos, ela é um recurso relevante a compreensão dos fundamentos da desigualdade e para a geração de uma nova institucionalidade no país". Neste sentido, a sujeição econômica de jovens e adultos trabalhadores não pode significar a expressão de sua incapacidade de construção de uma sociedade para além da exploração capitalista. Ou seja, o retorno aos bancos escolares deve propiciar o domínio de saberes qualificadores para uma intervenção social mais consciente e mais autônoma. Uma formação que promova a integração entre a preparação para o mundo do trabalho e a constituição de um sujeito político interventor, capaz de aglutinar conhecimentos que o possibilitem ler a realidade social e política e definir-se por um dos projetos de classe em disputa (DELUIZ, 1997). É este projeto político-pedagógico, que visa à autonomia e à maturidade intelectual dos trabalhadores, que os defensores de projetos como "Escola Sem Partido" visam impedir.

Se para alguns professores a proposta de EJA aqui defendida não possui base concreta com a realidade, dado o sucateamento das escolas públicas, os baixos salários docentes e o aprofundamento da precarização das relações de trabalho, reafirmamos a dimensão política da escola e que educar é um ato político (FREIRE, 2003), o que nos impõe a refletir sobre o tipo de sociedade que visamos quando educamos. Como ressalta Ramos (2008), visamos uma sociedade que exclui, discrimina, fragmenta os sujeitos e nega direitos; ou uma sociedade que 
inclui, reconhece a diversidade, valoriza os sujeitos e sua capacidade de produção da vida, assegurando direitos sociais plenos?

Defendemos aqui a necessidade de fortalecer as práticas político-pedagógicas da EJA no diálogo com Paulo Freire, Antonio Gramsci e demais autores da contemporaneidade que nos encorajam na luta cotidiana por uma educação pública, gratuita, universal, laica e de qualidade, inspirada nos princípios de liberdade e nos ideais de solidariedade humana. Uma educação que tenha por finalidade o pleno desenvolvimento do educando, seu preparo para o exercício da cidadania e sua qualificação para o trabalho, tal como expressa o Artigo $2^{\circ}$ da Lei de Diretrizes e Bases da Educação.

\section{REFERÊNCIAS}

ARRIGHI, G. A ilusão do desenvolvimento. 6 ed. Petrópolis: Vozes, 1997.

BRASIL. Constituição da República Federativa do Brasil. Brasília, DF: Senado Federal, 1988.

BRASIL. Lei n. 9394/96 de 20 de dezembro de 1996. Estabelece as Diretrizes e Bases da Educação Nacional. Diário Oficial da União, Brasília, 23 dez. 1996. p. 27833.

CASTEL, R. As metamorfoses da questão social: uma crônica do salário. Petrópolis, RJ: Vozes, 1998.

CIAVATTA, M. A formação integrada: a escola e o trabalho como lugares de memória e de identidade. In: FRIGOTTO, G. et al. (orgs.) Ensino médio integrado: concepções e contradições. São Paulo: Cortez, 2005.

DEL PINO, M. Política educacional, emprego e exclusão social. In: GENTILI; P.;

FRIGOTTO, G. A cidadania negada: políticas de exclusão na educação e no trabalho. 3. ed. - Rio de Janeiro: Cortez [Buenos Aires, Argentina]: CLACSO, 2002.

DELUIZ, N. Projetos em disputa: empresários, trabalhadores, trabalhadores e a formação profissional. Revista Trabalho e Educação, Belo Horizonte, n. 1, p. 113-127, fev./jul., 1997. Disponível em: https://seer.ufmg.br/index.php/trabedu/article/view/7265/5635. Acesso em: 20 fev. 2016.

FERNANDES, F. Capitalismo dependente e classes sociais na América Latina. 2. ed. Rio de Janeiro: Zahar, 1975.

FREIRE, P. Pedagogia da Aautonomia: saberes necessários á prática educativa. 28. Ed. São Paulo: Paz e Terra, 2003

FREIRE, P. Conscientização: teoria e prática da libertação. Uma introdução ao pensamento de Paulo Freire. 3. ed. São Paulo: Editora Moraes, 1980. 
FRIGOTTO, G. A gênese das teses do Escola sem Partido: esfinge e ovo da serpente que ameaçam a sociedade e a educação. In: FRIGOTTO, G. (Org.). Escola "sem" partido: esfinge que ameaça a educação e a sociedade brasileira. Rio de Janeiro: UERJ, LPP, 2017.

GENTILI, P. Educar para o desemprego. In: FRIGOTTO, G. (org.). Educação e crise do trabalho: perspectiva de final de século. Petrópolis, RJ: Vozes, 1998.

GRAMSCI, A. Os Intelectuais orgânicos e a organização da cultura. 9. ed. Rio de Janeiro: Civilização Brasileira, 1995.

HARVEY. A condição pós-moderna. 4. ed. São Paulo: Edições Loyola, 1994.

KUENZER, A. Educação profissional: categorias para uma nova pedagogia do trabalho.

Boletim Técnico do SENAC. Rio de Janeiro, v. 25, n. 2, maio/ago., p. 19-29, 1999.

MANACORDA, M. A. Marx e a pedagogia moderna. São Paulo: Cortez, 1991.

MARX, K. Manuscritos econômico-filosóficos e outros textos escolhidos. São Paulo: Abril Cultural, Coleção Os Pensadores, 2. ed. 1978.

POCHMANN, M. Educação e Trabalho: como desenvolver uma relação virtuosa? Educação e Sociedade, Campinas, v. 25, n. 87, p. 383-399, maio/ago., 2004.

SCHULTZ, T. Capital humano. Rio de Janeiro: Zahar, 1973.

SOUZA, J. dos S. A EJA no contexto das políticas públicas de inclusão de jovens no mercado de trabalho. In: SOUZA, J. dos S.; SALES, S. R. (orgs.). Educação de jovens e adultos:

políticas e práticas educativas, Rio de Janeiro: Nau Editora, EDUE-UFRRJ, 2011.

RAMOS, M. N. Concepção do ensino médio integrado, 2008. Disponível em:

http://forumeja.org.br/go/sites/forumeja.org.br.go/files/concepcao_do_ensino_medio_integrad o5.pdf. Acesso em: 16 set 2014.

\section{Como referenciar este artigo}

BARBOSA, C. S. A educação de jovens e adultos na perspectiva da formação humana: desafios no contexto das relações flexíveis de trabalho. Revista Ibero-Americana de Estudos em Educação, Araraquara, v. 14, n. 1, p. 63-76, jan./mar., 2019. E-ISSN: 19825587. DOI: $10.21723 /$ riaee.v14i1.11114

Submissão: $27 / 02 / 2018$

Revisões requeridas: 23/04/2018

Aprovação final: 29/07/2018 